\title{
Five-Year Meteorological Data Base for the MACCS Computer Code (U)
}

\author{
C. H. Hunter \\ Westinghouse Savannah River Company \\ Aiken, SC 29808
}


This document was prepared in conjunction with work accomplished under Contract No. DE-AC09-96SR18500 with the U. S. Department of Energy.

\section{DISCLAIMER}

This report was prepared as an account of work sponsored by an agency of the United States Government. Neither the United States Government nor any agency thereof, nor any of their employees, makes any warranty, express or implied, or assumes any legal liability or responsibility for the accuracy, completeness, or usefulness of any information, apparatus, product or process disclosed, or represents that its use would not infringe privately owned rights. Reference herein to any specific commercial product, process or service by trade name, trademark, manufacturer, or otherwise does not necessarily constitute or imply its endorsement, recommendation, or favoring by the United States Government or any agency thereof. The views and opinions of authors expressed herein do not necessarily state or reflect those of the United States Government or any agency thereof.

This report has been reproduced directly from the best available copy.

Available for sale to the public, in paper, from: U.S. Department of Commerce, National Technical Information Service, 5285 Port Royal Road, Springfield, VA 22161, phone: (800) 553-6847, fax: (703) 605-6900

email: orders@ntis.fedworld.gov

online ordering: http://www.ntis.gov/help/index.asp

Available electronically at http://www.osti.gov/bridge

Available for a processing fee to U.S. Department of Energy and its contractors, in paper, from: U.S. Department of Energy, Office of Scientific and Technical Information, P.O. Box 62, Oak Ridge, TN 37831-0062,

phone: (865)576-8401,

fax: (865)576-5728

email: $\underline{\text { reports@ adonis.osti.gov }}$ 


\section{Computer Code}

\section{Executive Summary}

This report describes development of a revised Savannah River Site (SRS) meteorological data set for the MELCOR Accident Consequence Code System (MACCS). This data set contains quality assured values of transport wind direction, wind speed, atmospheric stability class, and precipitation for all hours in each of the five years 1997-2001. Measurements collected from the SRS H-area meteorological tower are the primary source for these data. Substitution was used to complete the data set for the 2 percent of hours in which data from the H-tower record were missing or invalid. Sources of data for substitution included, in order of preference: quality assured data from one of the other seven primary onsite towers, an interpolation of valid H-tower data over short intervals (less than 12 hours) when no other onsite data were available, and data from Georgia Power Company's Plant Vogtle meteorological tower for intervals of missing SRS data greater than 12 hours. Data used to construct the MACCS data set was subject to extensive quality assurance review. The SRS meteorological monitoring program, quality assurance methods, and applicable formats for the MACCS data sets are described. Previous MAACS data sets contained data for the five-year periods 1982-1986, 1987-1991, and 1992-1996. The data set for 1997-2001 is available on CD from the Savannah River Technology Center, Atmospheric Technologies Group. 


\section{Overview of the SRS Meteorological Monitoring Program}

Meteorological data are collected from a network of nine monitoring stations across the SRS (Fig. 1). Towers located adjacent to each of eight primary operations areas (A, C, $\mathrm{D}, \mathrm{F}, \mathrm{H}, \mathrm{K}, \mathrm{L}$, and $\mathrm{P}$ areas) are equipped to measure horizontal and vertical components of wind direction, wind speed, temperature, and dew point at a height of 61-meters (m) above ground. A ninth tower near N-Area, known as the Central Climatology site (CLM), is instrumented with wind, temperature, and dew point sensors at four levels: $2 \mathrm{~m}$, $18 \mathrm{~m}, 36 \mathrm{~m}$, and $61 \mathrm{~m}$. The CLM site is also equipped with an automated tipping bucket rain gage, a barometric pressure sensor, and a solar radiometer near the tower at ground level. Data acquisition units at each site record measurements from the instruments at 1second intervals. Every 15 minutes, the 1 -second data are processed to generate averages and standard deviations for each variable, and the results uploaded to an Oracle database for permanent archival. This database of 15-minute values resides on the Savannah River Technology Center's VMS computer cluster.

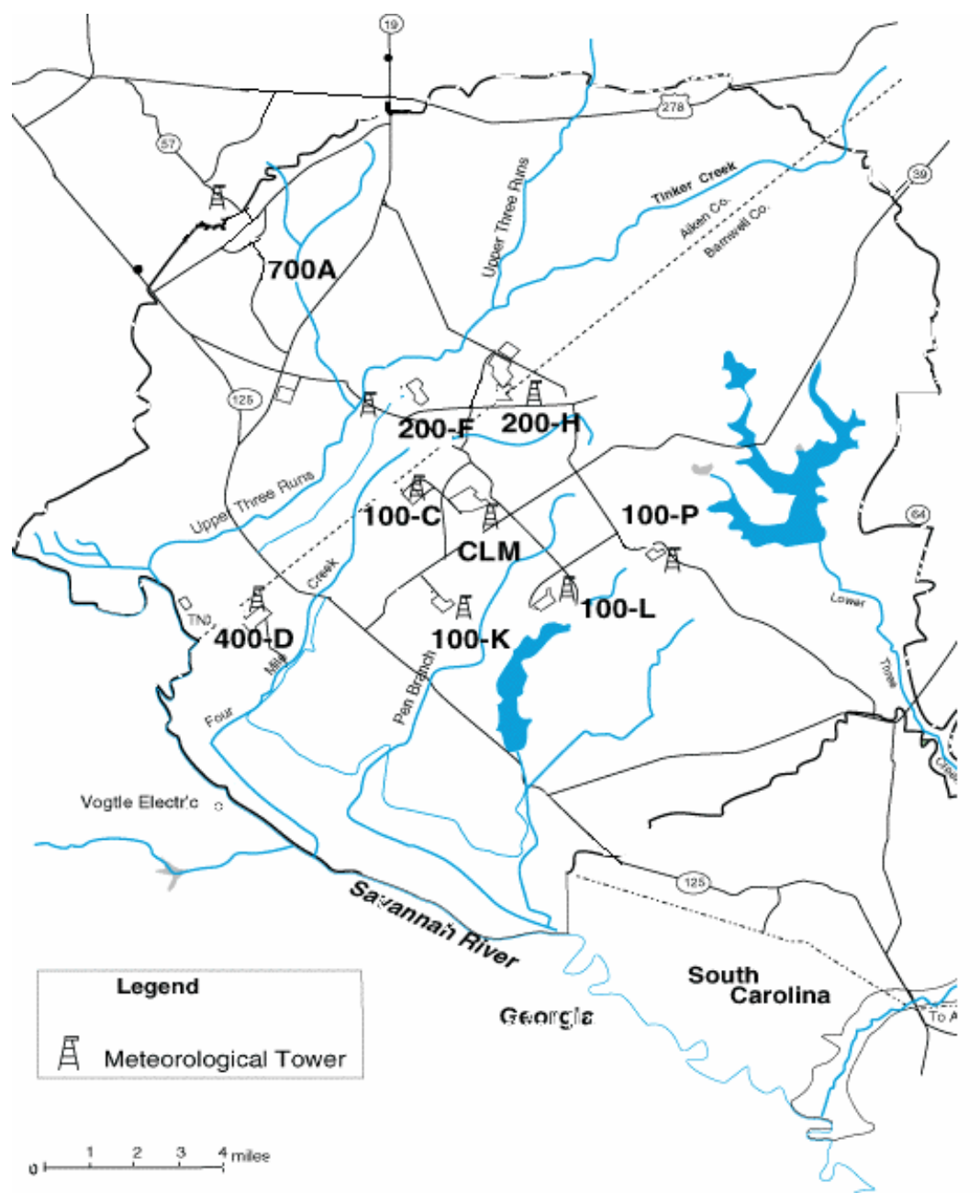

Fig. 1. Map of the SRS Meteorological Tower Locations. 
All aspects of the meteorological data collection program meet or exceed applicable regulatory criteria (DOE,1991; EPA, 2000; ANSI, 2000) guidance, including instrument performance specifications, siting, calibration, and quality assurance protocols. Parker, et al, (1993) provide a complete description of the SRS meteorological monitoring program.

Quality assurance of meteorological data is conducted in a two-step process: an initial screening of recently collected data, followed later with an in-depth data review and quality classification. The initial screening, performed twice daily by qualified instrument technicians, consist of a thorough examination of 15-minute data retrieved from the database followed by a review of instrument diagnostics generated by the local data acquisition units. Potential problems are noted in a daily checksheet and real-time data quality tags are assigned to data collected from questionable instruments, as necessary, through remote interrogation of the appropriate data acquisition unit. Data quality tags are also set at the data acquisition units during periods of calibration and maintenance.

The second step of the quality assurance process is conducted periodically as prescribed by formal procedure (SRTC, 2002). Daily checksheets generated during the initial screening, tower-specific logbook entries, and time series plots of related data are reviewed to determine a final quality status of each data point. All data records in the data base are tagged as good, fatal, intermittent, biased, or uncalibrated.

Installation of new data acquisition units at each the towers in 1998 has resulted in considerable improvement in data capture. A review of the records indicates that the most significant causes of lost data for the 5-year period were instrument icing, lightning damage, and calibration periods.

\section{Development of a 5-year Data Base for Critical Modeling Applications}

Weber (2002) used quality assured data from the archived database to develop a common 5-year database that meets the generic requirements of most atmospheric dispersion models used in critical safety applications at SRS. This database consists of a complete sequential record of hourly averaged wind direction (azimuth), flow (transport) direction, wind speed, standard deviation of horizontal wind direction (sigma-azimuth), standard deviation of vertical angle (sigma-elevation), temperature and dew point. Most of the data in this data set are from the SRS H-Area tower.

Initially, fifteen minute data from all SRS towers with a quality attribute of 'good' were extracted from the archive and subject to a final instrument range and zero value check. Missing or invalid periods in $\mathrm{H}$-area tower record with were the filled with valid data from surrounding onsite towers (F, C, L, P, K, A, and D towers, respectively). The resulting 15-minute data set was then processed to create a record of hourly values.

Wind direction was converted to a flow (transport) direction and processed to yield hourly values as vector averages. Scalar averaging was used for wind speed, 
temperature and dew point. Hourly values for sigma-azimuth and sigma-elevation were determined from an interative application of the following general expression for combining the standard deviations of two data sets:

$\sigma_{c}=\sqrt{\frac{\left(N_{1}-1\right) \sigma_{1}{ }^{2}+\left(N_{2}-1\right) \sigma_{2}{ }^{2}+0.25\left(N_{1}+N_{2}\right)\left(m_{1}-m_{2}\right)^{2}}{N_{1}+N_{2}-1}}$

where $m_{1}$ and $m_{2}$ are the averages of the two data sets, $\sigma_{1}$ and $\sigma_{2}$ are the standard deviations, and $N_{1}$ and $N_{2}$ are the number of observations in each data set (Laurinat, 1987). For this application, $N_{1}$ and $N_{2}$ equal 900 (one observation per second for 15 minutes) and $m_{1}$ and $m_{2}$ are the average wind directions. Combined sigma-azimuth and sigma elevation are determined for the first two, then second two, 15-minute periods in an hour. Finally, the two sets of 30-minute values are combined to produce an hourly result. Using this method, the hourly values of sigma-azimuth and sigmaelevation include both short term wind direction fluctuations within the 15-minute period and shifts in mean wind direction occurring over the hour.

Each hour in the record was required to have at least two 15-minute periods of data present; otherwise the hour was considered missing.

Two additional processing steps were performed to develop a complete sequential data base. For any missing period lasting less than 12 hours, substitute data was derived from a linear interpolation between the two bounding valid hours. Missing periods greater than 12 hours were filled with data from Georgia Power Company's Plant Vogtle (a 60-meter tower located 12 miles south-southwest of $\mathrm{H}$ area).

Valid data recovery for $\mathrm{H}$-area wind and temperature data for the 5-year period was approximately $98 \%$. Most of the missing hours were filled with data from the F-area tower; data substitution from other SRS towers, interpolation, or Plant Vogtle account for less than $0.2 \%$ of hours in the five-year period.

A complete description of the development of this common dataset is given by Weber (2002). 


\section{Preparation of the MACCS Data Set}

The updated data sets for MACCS were prepared according to the MACCS format specifications summarized in Table 1.

Table 1. Format of the MACCS Meteorological Data Files

\begin{tabular}{|c|c|c|c|}
\hline Column & Format & Description & $\begin{array}{c}\text { Range of } \\
\text { Values }\end{array}$ \\
\hline $2-4$ & I3 & Julian Day & $1-366$ \\
\hline $6-7$ & I2 & Hour of the Day (UTC) & $1-24$ \\
\hline $9-10$ & I2 & $\begin{array}{c}\text { Transport Sector (direction } \\
\text { wind blows toward) }\end{array}$ & $1-16$ \\
\hline $11-13$ & I3 & $\begin{array}{c}\text { Wind speed } \\
\text { (10ths of meters / sec) }\end{array}$ & $1-300$ \\
\hline 14 & I1 & Stability Class & $1-7$ \\
\hline $15-17$ & I3 & $\begin{array}{c}\text { Total Precipitation } \\
\text { (100ths of inches) }\end{array}$ & $0-999$ \\
\hline
\end{tabular}

A SAS (Statistical Analysis System) routine MACCS_NEW.SAS executed on the Savannah River Technology Center VMS computer cluster was used to perform the following processing:

(1) Extract hourly values of transport wind direction (direction toward which the wind blows), wind speed, and sigma-azimuth (standard deviation of horizontal wind direction fluctuations) from the hourly database developed by Weber (2002).

(2) Assign values for the wind transport sector (Table 2) and stability class (Table 3) from data obtained through step (1).

(3) Adjust wind speed to the reference height of $10 \mathrm{~m}$ above ground using a standard power law interpolation (EPA, 2000).

(4) Write the results to a temporary file in the MACCS format.

Temporary files for each of the five years were then downloaded from the VMS cluster to a PC and placed in an Excel spreadsheet for final processing.

Stability classification was based on the hourly values of sigma-azimuth. The classification scheme recommended by the Nuclear Regulatory Commission (NRC, 1980) was applied to accommodate the MAACS requirement for seven stability categories. 
Table 2. Determination of Transport Sector

\begin{tabular}{|c|c|c|}
\hline $\begin{array}{c}\text { Transport Direction } \\
\text { (degrees) }\end{array}$ & Compass Sector & $\begin{array}{c}\text { MACCS } \\
\text { Sector } \\
\text { Identifier }\end{array}$ \\
\hline $348.75-11.24$ & North & 1 \\
\hline $11.25-33.74$ & North-northeast & 2 \\
\hline $33.75-56.24$ & Northeast & 3 \\
\hline $56.25-78.74$ & East-northeast & 4 \\
\hline $78.75-101.24$ & East & 5 \\
\hline $101.25-123.74$ & East-southeast & 6 \\
\hline $123.75-146.24$ & Southeast & 7 \\
\hline $146.25-168.74$ & South-southeast & 8 \\
\hline $168.75-191.24$ & South & 9 \\
\hline $191.25-213.74$ & South-southwest & 10 \\
\hline $213.75-236.24$ & Southwest & 11 \\
\hline $236.25-258.74$ & West-southwest & 12 \\
\hline $258.75-281.24$ & West & 13 \\
\hline $281.25-303.74$ & West-northwest & 14 \\
\hline $303.75-326.24$ & Northwest & 15 \\
\hline $326.25-348.74$ & North-northwest & 16 \\
\hline
\end{tabular}

Table 3. Atmospheric Stability Identifiers

\begin{tabular}{|c|c|c|}
\hline $\begin{array}{c}\text { Sigma-azimuth } \\
\text { Range (degrees) }\end{array}$ & Pasquill Category & $\begin{array}{c}\text { MAACS } \\
\text { Stability } \\
\text { Identifier }\end{array}$ \\
\hline 22.5 or greater & $\mathrm{A}$ & 1 \\
\hline $17.5-22.5$ & $\mathrm{~B}$ & 2 \\
\hline $12.5-17.5$ & $\mathrm{C}$ & 3 \\
\hline $7.5-12.5$ & $\mathrm{D}$ & 4 \\
\hline $3.8-7.5$ & $\mathrm{E}$ & 5 \\
\hline $2.1-3.8$ & $\mathrm{~F}$ & 6 \\
\hline Less than 2.1 & $\mathrm{G}$ & 7 \\
\hline
\end{tabular}


Wind speed was interpolated to the 10 meter reference level using the following power law expression suggested by EPA (2000):

$\mathrm{u}_{61}=\mathrm{u}_{10}(61 / 10) \mathrm{p}$

where $\mathrm{u}_{61}$ is the measured 61-meter wind speed and $\mathrm{u}_{10}$ is the reference wind speed. The exponent $\mathrm{p}$ is dependent on stability, as follows:

Class A, $\quad \mathrm{p}=0.07$

Class B, $\quad \mathrm{p}=0.07$

Class $C, \quad \mathrm{p}=0.10$

Class $\mathrm{D}, \quad \mathrm{p}=0.15$

Class E, $\quad \mathrm{p}=0.35$

Class $\mathrm{F}, \quad \mathrm{p}=0.55$

Class $\mathrm{G}, \quad \mathrm{p}=0.55$

The EPA guidance does not give a value of $p$ for G stability; a value equal to that of Class F was assumed. An example listing of the MACCS_NEW.SAS routine is given in Appendix A.

Precipitation data for MACCS was processed using the SAS routine MACCS_RAIN.SAS. This routine extracts from the original archive database all 15 minute values recorded by the CLM rain gage with a quality tag of 'good', then sums the available 15-minute values over each hour of year. An example listing of the MAACS_RAIN routine is given in Appendix B.

Temporary files containing the hourly totals, and the number of valid 15-minute periods that comprise the hourly total, were then downloaded from the VMS cluster to a PC and placed in an Excel spreadsheet. The files were manually inspected to determine periods of missing or incomplete hours. Hours were considered incomplete if less than three valid periods were available. Supplemental data for the missing or incomplete periods were taken from hourly rainfall measurements recorded at the National Weather Service (NWS) office in Augusta, GA, approximately $20 \mathrm{~km}$ west of the CLM site. The NWS data were extracted from a CD (Earthinfo, 2001) containing historical records maintained by the National Climate Data Cener (NCDC), and manually entered into the temporary Excel spreadsheet.

The complete record of precipitation data was then merged with the hourly wind and stability data. All data were subject to a final manual inspection, and exported from Excel in the MAACS format as ASCII text files. Each file was edited to add an 
identification header as the first record of the file, and to add seasonally averaged values of morning and afternoon mixing height values (in hundreds of meters), in 8F10.0 format, as the last record of the file. The seasonally averaged mixing heights were determined from daily values that were obtained from the NCDC and imported into an Excel spreadsheet. The daily mixing heights were calculated by NCDC using the EPA Mixing Height program. These calculations were based on Atlanta, GA upper air data and Augusta, GA surface data for the five years 1997-01.

As a final check on data processing, each of the five annual files were fully reviewed and manually spot checked against the master hourly data base and the original 15minute archive data base.

\section{Climatological Characteristics of the 1997-2001 Data Set}

Percent occurrence frequencies of the sixteen wind transport sectors by six wind speed categories for the five year data set are summarized in Table 4 and Figure 2 . These data show a slight preference in transport direction toward the northeast to east sectors (ranging between $8 \%$ and $10 \%$ of all hours) and toward the southwest sector ( $8 \%$ of all hours). The average estimated $10-\mathrm{m}$ wind speed for the five year period was about $3 \mathrm{~m} / \mathrm{s}$. Hourly wind speeds between 2 and $4 \mathrm{~m} / \mathrm{s}$ occur nearly $64 \%$ of the hours in the five-year record, and $97 \%$ of all hours have $10-\mathrm{m}$ wind speeds of $6 \mathrm{~m} / \mathrm{s}$ or less.

Table 5 provides a summary of the percent occurrence of Pasquil stability class by year and for all hours in the 5-year data set. Stable conditions that are relatively

Table 4. Percent occurrence of wind direction sector by wind speed category for hours in the MACCS five-year meteorological data set for 1997-2001.

\begin{tabular}{|c|c|c|c|c|c|c|c|}
\hline $\begin{array}{c}\text { Sectorl } \\
\text { Speed (m/s) }\end{array}$ & $\mathbf{0 - 2}$ & $\mathbf{2 - 4}$ & $\mathbf{4 - 6}$ & $\mathbf{6 - 8}$ & $\mathbf{8 - 1 2}$ & $\mathbf{> 1 2}$ & All \\
\hline $\mathbf{N}$ & 1.198 & 4.707 & 1.248 & 0.087 & 0.023 & 0.000 & 7.263 \\
NNE & 1.120 & 4.550 & 0.917 & 0.114 & 0.011 & 0.000 & 6.713 \\
NE & 1.228 & 5.415 & 1.401 & 0.205 & 0.023 & 0.000 & 8.272 \\
ENE & 1.401 & 6.253 & 1.901 & 0.315 & 0.023 & 0.000 & 9.892 \\
ENE & 1.223 & 4.860 & 1.709 & 0.482 & 0.066 & 0.000 & 8.340 \\
ESE & 1.166 & 3.646 & 1.278 & 0.438 & 0.069 & 0.000 & 6.596 \\
SE & 1.100 & 2.012 & 0.495 & 0.073 & 0.023 & 0.000 & 3.703 \\
SSE & 1.025 & 1.778 & 0.297 & 0.039 & 0.023 & 0.000 & 3.160 \\
S & 0.844 & 2.295 & 0.698 & 0.057 & 0.069 & 0.000 & 3.963 \\
SSW & 1.228 & 4.180 & 1.082 & 0.137 & 0.011 & 0.000 & 6.638 \\
SW & 1.358 & 5.378 & 1.118 & 0.042 & 0.000 & 0.000 & 7.896 \\
WSW & 1.047 & 4.959 & 1.004 & 0.064 & 0.046 & 0.000 & 7.120 \\
W & 0.940 & 3.982 & 0.582 & 0.029 & 0.023 & 0.000 & 5.556 \\
WNW & 1.107 & 3.478 & 0.463 & 0.034 & 0.011 & 0.000 & 5.094 \\
\hline
\end{tabular}


Five-Year Meteorological Data Base for the MACCS

Computer Code

WSRC-RP-2003-00608

\begin{tabular}{|c|c|c|c|c|c|c|c|}
\hline NW & 1.161 & 2.855 & 0.584 & 0.029 & 0.000 & 0.000 & 4.629 \\
\hline NNW & 1.116 & 3.220 & 0.981 & 0.082 & 0.011 & 0.000 & 5.410 \\
\hline All & 18.262 & 63.568 & 15.759 & 2.226 & 0.431 & 0.000 & 100 \\
\hline
\end{tabular}

Fig. 2. Wind transport rose of wind direction sector by wind speed category for hours in the MACCS five-year meteorological data set for 1997-2001. Transport direction expresses the direction toward which the wind blows.
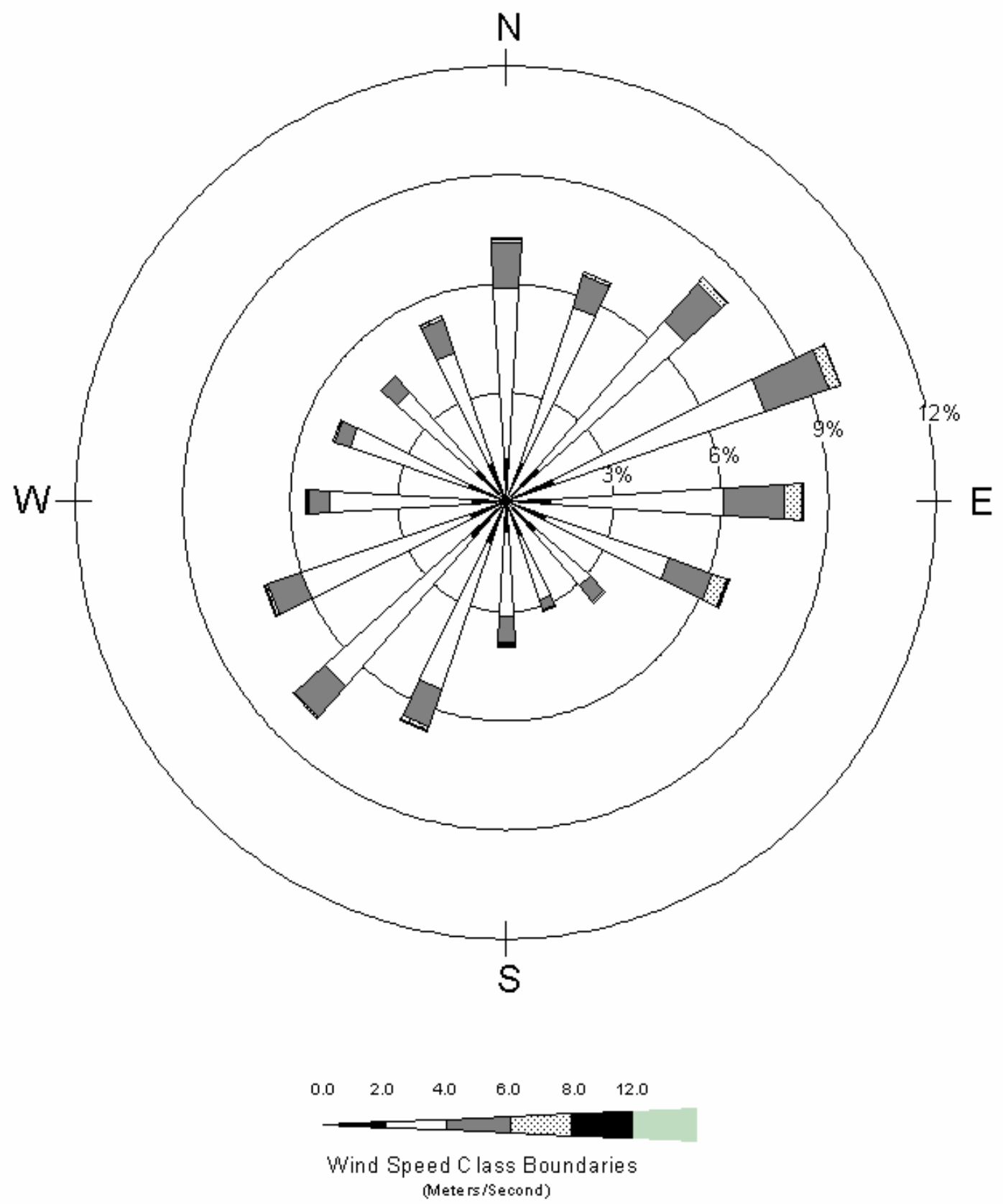
unfavorable for long-range dispersion of an airborne pollutant (classes E, F, and G) occurred about 18 percent of hours in the five year period; conditions favorable for long-range dispersion (classes A, B, and C) occurred on more than $60 \%$ of the hours. Occurrence frequencies for each stability class show little interannual variability.

Table 5. Percent Frequency of Occurrence of P-G Stability Class for hours in the MACCS five-year meteorological data set for 1997-2001.

\begin{tabular}{|c|c|c|c|c|c|c|}
\hline $\begin{array}{c}\text { Yearl } \\
\text { Pasquill } \\
\text { Class }\end{array}$ & $\mathbf{1 9 9 7}$ & $\mathbf{1 9 9 8}$ & $\mathbf{1 9 9 9}$ & $\mathbf{2 0 0 0}$ & $\mathbf{2 0 0 1}$ & $\mathbf{5 - Y r}$ Avg \\
\hline A & 26.7 & 27.0 & 25.9 & 26.7 & 26.3 & 26.5 \\
\hline B & 14.3 & 13.5 & 14.4 & 14.5 & 15.0 & 14.3 \\
\hline C & 20.3 & 21.1 & 20.1 & 20.1 & 17.8 & 19.9 \\
D & 21.7 & 21.0 & 21.4 & 21.1 & 21.8 & 20.1 \\
\hline E & 14.1 & 14.8 & 15.7 & 14.6 & 16.5 & 15.1 \\
\hline F & 2.7 & 2.4 & 2.5 & 2.8 & 2.5 & 2.6 \\
\hline G & 0.3 & 0.2 & 0.1 & 0.2 & 0.1 & 0.2 \\
\hline
\end{tabular}

Precipitation statistics summarized in Table 6 show that the 5-year period of record was characterized by two relatively wet years (1997 and 1998) and three relatively dry years (1999-2001). Light precipitation occurs (less than one-tenth of an inch) occurs on $75 \%$ of the hours that precipitation occurs. Precipitation characterized as heavy (greater than one-half inch) occurs infrequently.

Table 6. Rainfall Statistics for the MACCS five-year meteorological data set for 1997-2001

\begin{tabular}{|c|c|c|c|c|c|c|}
\hline & $\mathbf{1 9 9 7}$ & $\mathbf{1 9 9 8}$ & $\mathbf{1 9 9 9}$ & $\mathbf{2 0 0 0}$ & $\mathbf{2 0 0 1}$ & 5-Yr Avg \\
\hline $\begin{array}{c}\text { Total } \\
\text { Rainfall, in } \\
\text { \% Hours } \\
\text { with rain }\end{array}$ & 58.7 & 56.8 & 40.4 & 37.3 & 38.3 & 46.3 \\
\hline \hline $\begin{array}{c}\text { \% of } \\
\text { Rainfall } \\
\text { Hours }\end{array}$ & $\mathbf{1 9 9 7}$ & $\mathbf{1 9 9 8}$ & $\mathbf{1 9 9 9}$ & $\mathbf{2 0 0 0}$ & $\mathbf{2 0 0 1}$ & $\mathbf{5 - Y r}$ Avg \\
\hline $\begin{array}{c}<\mathbf{0 . 0 1} \text { in } \\
\mathbf{0 . 0 1 - 0 . 1} \text { in }\end{array}$ & 22.6 & 24.3 & 23.1 & 27.8 & 31.0 & 25.8 \\
\hline
\end{tabular}




\begin{tabular}{|c|c|c|c|c|c|c|}
\hline $\mathbf{0 . 1}-\mathbf{0 . 5}$ in & 25.9 & 23.8 & 18.9 & 16.1 & 16.4 & 20.2 \\
\hline$>0.5$ in & 3.0 & 4.1 & 2.2 & 2.9 & 4.5 & 3.3 \\
\hline
\end{tabular}

\section{References}

American Nuclear Society, American National Standard for Determining Meteorological Information at Nuclear Facilities, ANSI/ ANS-3.11-2000 (2000).

Earthinfo, Inc., NCDC Hourly Precipitation - East 2001.

J. E. Laurinat, Meteorological Data for PRA Offsite Consequence Analysis, DPST-87-513, E. I. duPont de Nemours and Company, (1987).

M. J. Parker and R. P. Addis, Meteorological Monitoring Program at the Savannah River Site, WSRC-TR-93-0106, Westinghouse Savannah River Company (1993).

Savannah River Technology Center - Nonproliferation Technologies Section, Quality Assurance of Meteorological Data, WSRC Procedure Manual 15.3, Meteorological Monitoring Procedures, NTSP T-113 (2002).

U. S. Department of Energy, Environmental Regulatory Guide for Radiological Effluent Monitoring and Environmental Surveillance, DOE EH-0173T, (1991)

U. S. Environmental Protection Agency, Meteorological Monitoring Guidance for Regulatory Modeling Applications, EPA-454/R-99-005 (2000).

U. S. Nuclear Regulatory Commission, Meteorological Programs for Nuclear Power Plants, Proposed Revision to Regulatory Guide 1.23 (1980).

A. H. Weber, Summary of Data and Steps for Processing the SRS 1997-2001 Meteorological Database, WSRC-TR-2002-00445, Westinghouse Savannah River Company (2002). 


\section{Appendix A. Listing of SAS routine MACCS_NEW.SAS for the 1997 annual period.}

* Data are read from the controlled qa'ed met data file maintained;

* maintained by A. Weber, variables are extracted as needed;

OPTIONS NOCENTER;

DATA ONE; SET OFFI_DAT.H_97_01;

FILENAME OUT 'XXXX:[XXXX.xxxx] maccstmp_97.DAT';

DT=DATEPART(FINETIM);

TM=TIMEPART(FINETIM);

$\mathrm{HR}=\operatorname{HOUR}(\mathrm{TM})+1$;

$\mathrm{YR}=\mathrm{YEAR}(\mathrm{DT})$;

IF YR = 1997;

FINEJUL=JULDATE(DT);

JULDAT=FINEJUL-97000;

${ }^{*}$ write direction as plume direction - NOT NEEDED FOR 92-96 DATA;

${ }^{*}$ MVVPL = MVVAZ + 180;

*IF (MVVPL > 360) THEN MVVPL = MVVPL - 360;

* Determine transport direction sector;

IF $(348.75<=$ MVVAZ)THEN AZSECTOR $=1$;

IF (11.25 > MVVAZ)THEN AZSECTOR=1;

IF $(11.25<=$ MVVAZ < 33.75) THEN AZSECTOR=2;

IF $(33.75<=$ MVVAZ < 56.25) THEN AZSECTOR=3;

IF $(56.25<=$ MVVAZ < 78.75) THEN AZSECTOR $=4$;

IF $(78.75<=$ MVVAZ < 101.25) THEN AZSECTOR=5;

IF $(101.25<=$ MVVAZ < 123.75) THEN AZSECTOR=6;

IF $(123.75<=$ MVVAZ < 146.25) THEN AZSECTOR=7;

IF $(146.25<=$ MVVAZ < 168.75) THEN AZSECTOR=8;

IF $(168.75<=$ MVVAZ < 191.25) THEN AZSECTOR=9;

IF $(191.25<=$ MVVAZ < 213.75) THEN AZSECTOR=10;

IF $(213.75<=$ MVVAZ < 236.25) THEN AZSECTOR=11;

IF $(236.25<=$ MVVAZ < 258.75) THEN AZSECTOR=12;

IF $(258.75<=$ MVVAZ < 281.25) THEN AZSECTOR=13;

IF $(281.25<=$ MVVAZ < 303.75) THEN AZSECTOR=14;

IF $(303.75<=$ MVVAZ < 326.25) THEN AZSECTOR=15;

IF $(326.25<=$ MVVAZ < 348.75) THEN AZSECTOR=16;

* write sigma-az as P-G stability classes based on sigma-az

* per EPA guidance;

IF ( MTSIG_AZ >= 22.5) THEN MSIG_PG $=1$; 
IF $(17.5<=$ MTSIG_AZ < 22.5) THEN MSIG_PG $=2$;

IF $(12.5<=$ MTSIG_AZ < 17.5) THEN MSIG_PG $=3$;

IF $(7.5<=$ MTSIG_AZ $<12.5)$ THEN MSIG_PG $=4$;

IF $(3.8<=$ MTSIG_AZ < 7.5) THEN MSIG_PG $=5$;

IF $(2.1<=$ MTSIG_AZ < 3.8) THEN MSIG_PG $=6$;

if $(0.1<=$ mtsig_az $<2.1)$ then msig_pg=7;

* adjust speed to $10 \mathrm{~m}$ ref height per simple

* power law;

if msig_pg $=1$ then mspd_10 $=$ mspeed $/ 1.13$;

if msig_pg $=2$ then mspd_10 $=$ mspeed $/ 1.13$;

if msig_pg $=3$ then mspd_10 = mspeed $/ 1.20$;

if msig_pg $=4$ then $\operatorname{mspd} \_10=$ mspeed $/ 1.31$;

if msig_pg $=5$ then mspd_10 $=$ mspeed $/ 1.88$;

if msig_pg $=6$ then $\operatorname{mspd} \_10=$ mspeed $/ 2.70$;

if msig_pg $=7$ then mspd_10 $=$ mspeed $/ 2.70$;

* WRITE TEMPERATURE IN DEG KELVIN;

*MTEMPK = MTEMP + 273.16;

* write adjusted wind speed in tenths $\mathrm{m} / \mathrm{sec}$;

$\operatorname{mspd} 10=\operatorname{mspd} \_10 * 10$;

FILE OUT;

PUT

@2 JULDAT 3.0

@6 HR 2.0

@10 AZSECTOR 2.0

@16 MSPd10 6.0

@24 MSIG_PG 2.0;

ENDSAS; 


\section{Appendix B. Listing of SAS routine MACCS_RAIN.SAS for the 1997 annual period.}

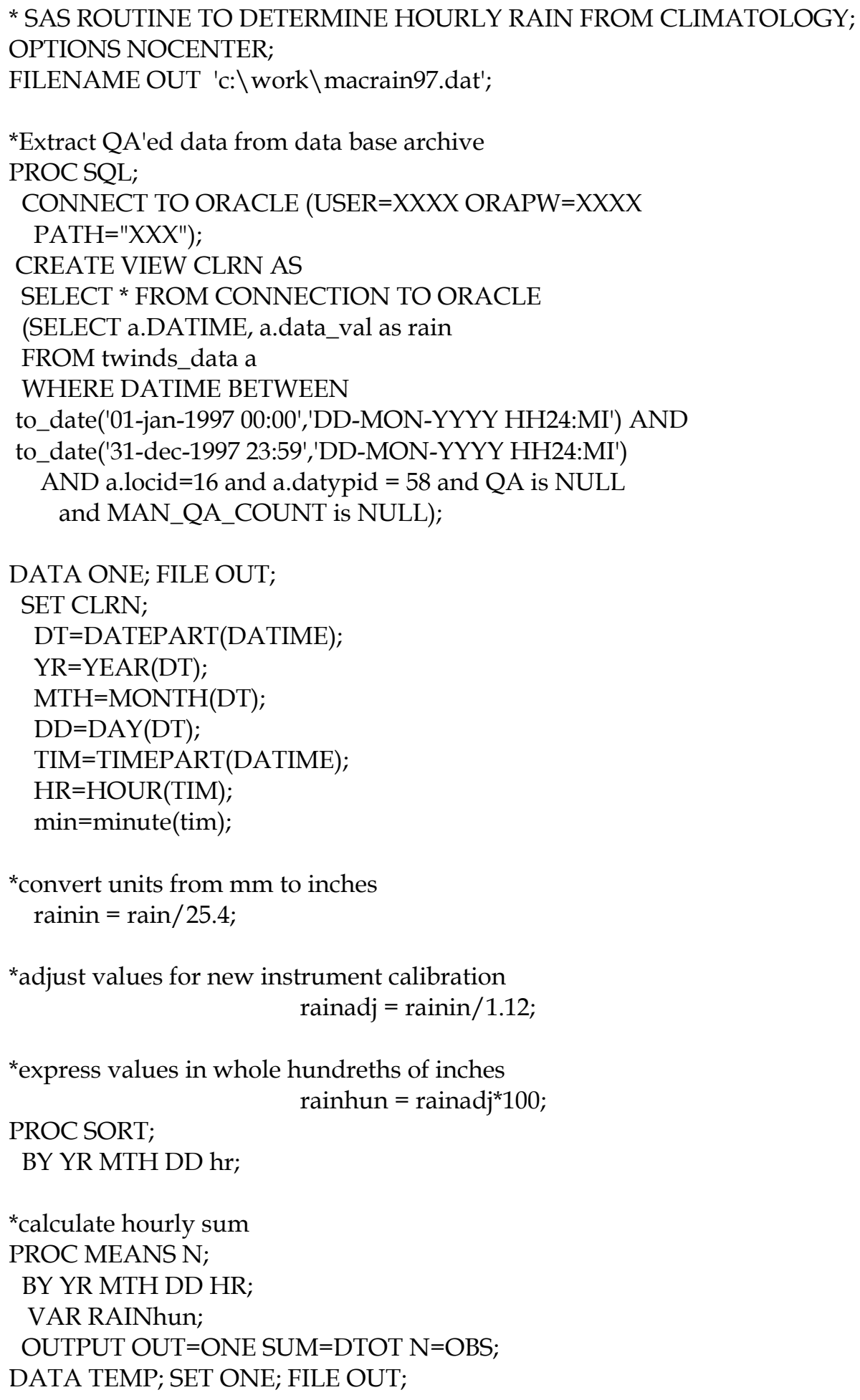




\author{
PUT \\ @1 mth 2.0 \\ @3 '-' \\ @ 4 dd 2.0 \\ @6 '-' \\ $@ 7$ yr 4.0 \\ @12 hr 2.0 \\ @18 dtot 6.1 \\ @25 obs 2.0; \\ endsas;
}

